\title{
The influence of employees' cross-cultural psychological capital on workplace psychological well-being
}

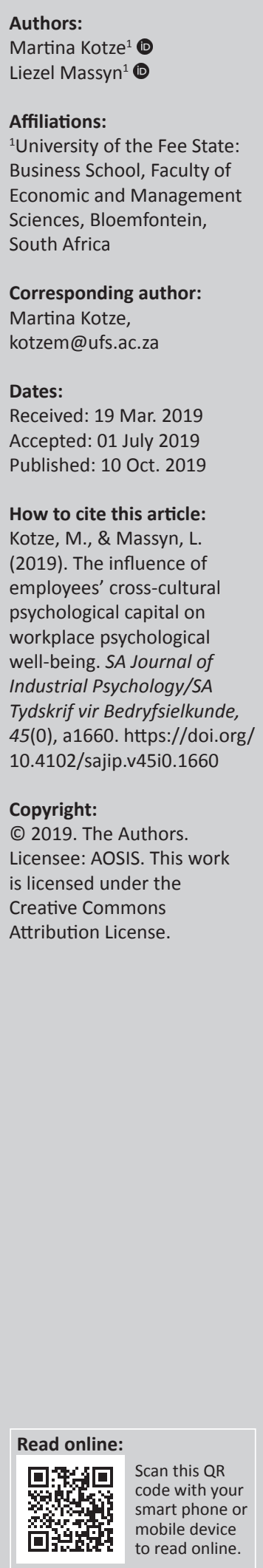

Orientation: In order to withstand the global and local cultural diversity and challenges that South African workplaces face, it is essential for employees to have cross-cultural psychological resources (i.e. cross-cultural psychological capital). A lack of cross-cultural psychological capital or the inability to adjust to cross-cultural environments may impact negatively employees' psychological well-being.

Research purpose: The purpose of this research was to explore the influence of employees' cross-cultural psychological capital on their psychological well-being (indicated by burnout and work engagement).

Motivation for the study: Cross-cultural psychological capital and its influence on employees' psychological well-being have not been explored in South Africa. This study aimed to fill this gap.

Research approach/design and method: Data were collected using questionnaires completed by 213 employees from different organisations in South Africa. Partial least squares (PLS) and structural equations modelling (SEM) were used to explore the relationships between the independent variable (cross-cultural psychological capital) and burnout and work engagement.

Main findings: Cross-cultural psychological capital had a statistically significant negative influence on burnout and a statistically significant positive influence on work engagement. It had a stronger negative influence on emotional exhaustion than on cynicism and a stronger positive influence on vigour than on dedication.

Practical/managerial implications: Enhancing employees' cross-cultural psychological capital by means of programmes and short interventions may improve their psychological well-being.

Contribution/value-add: This research contributed to filling the gap in the literature regarding the role of cross-cultural psychological capital in the psychological well-being of employees working in cross-cultural environments.

Keywords: Cross-cultural Competencies; Psychological Well-being; Cross-cultural; PsyCap; Burnout; Work engagement.

\section{Introduction}

Workplaces across the world and in South Africa have become culturally more diverse than ever before as employees from various cultural groups strive to achieve work objectives together. Cross-cultural diversity has many advantages, such as better problem-solving, higher motivation and less racial segregation. Therefore, organisations that are capable of effectively managing intercultural interactions will outperform those organisations that are less able to do so. In general, cross-cultural competence is defined as the ability to help 'create an effective work environment in cross-cultural situations' (Johnson, Lenartowicz, \& Apud, 2006, p. 529). Cross-culturally diverse workplaces that lack cross-cultural competency often struggle with issues such as difficulties in communication, misunderstandings and a lack of trust. Such workplaces may not only influence the organisation's performance negatively but also affect the psychological well-being of its employees (Ang \& Inkpen, 2008; Chatman \& Flynn, 2001; De Dreu \& West, 2001; Potgieter, 2017; Serfontein, 2014; Urciuoli, 2010).

The Job Demands-Resources (JD-R) model (Bakker \& Demerouti, 2008) helps us to understand how demands in the work environment can be mitigated by job and personal resources in order for employees to obtain positive work outcomes. The model shows how job demands (e.g. institutional ethnocentrism or cross-cultural difficulties) can be mitigated by job resources 
(e.g. diversity training) or personal resources (e.g. individuals' cross-cultural competencies) to obtain work outcomes such as psychological well-being (Johnson et al., 2006; Ng \& Earley, 2006). Regarding the role of personal resources in this model, past research showed the importance of intellectual, social and psychological capital as key in global leaders' ability to be effective in cross-cultural environments (Javidan \& Teagarden, 2011). Building on the work of Javidan and Teagarden (2011), Dollwet and Reichard (2014) introduced the construct 'cross-cultural psychological capital' (crosscultural PsyCap) by applying workplace PsyCap (Luthans, Youssef \& Avolio, 2007) to cross-cultural contexts. They focused on how PsyCap as a personal resource may enable employees to interact across cultures in a more effective manner. In addition to the JD-R model, Hobfoll's $(2002,2011)$ conservation of resources (COR) theory further explains how individuals constantly try to secure resources to help them attain or maintain psychological well-being, and avoid psychological distress. Cross-cultural PsyCap represents such 'a type of cross-cultural dynamic competency in the family of personal resources' and 'can be regarded as a crosscultural personal resource in Hobfoll's (2002, 2011) COR theory's resource family' (Liu, 2014, p. 83). As a resource, it may help employees to be less vulnerable in demanding cross-cultural situations.

While many South African organisations are pressurised to expand globally or to manage diverse workplaces locally, the 2018 Human Capital Trends Reports for South Africa listed employee well-being as the third most important priority that needs immediate attention (Deloitte, 2018). Therefore, it is important to explore ways in which the psychological wellbeing of South African employees can be enhanced within demanding cross-cultural work environments. Schaufeli and Bakker (2004) regard work engagement and burnout as indicators of employees' psychological well-being. To contribute to the empirical body of research relating to the role of cross-cultural personal resources in the enhancement of work engagement and the management of burnout, this study explored the role of cross-cultural PsyCap. Despite the importance of the PsyCap domain, the influence of crosscultural PsyCap on employees' psychological well-being has not been explored in South Africa. Therefore, this study aims to fill this gap in the South African literature on cross-cultural PsyCap.

\section{Literature review Cross-cultural psychological capital}

The construct cross-cultural PsyCap is based on Luthans et al.'s (2007) work on workplace PsyCap, but is anchored in cross-cultural interactions. Workplace PsyCap is a recognised core construct that has its roots in positive psychology and positive organisational behaviour (POB) (Luthans \& YoussefMorgan, 2017). It is a higher order construct that consists of four first-order constructs, namely, self-efficacy, hope, optimism and resilience. Workplace PsyCap is contextspecific, as it relates to employees' belief that they have the ability to execute their work tasks effectively (self-efficacy); set challenging, but realistic work goals and create alternative pathways to achieve it (hope); expect positive work outcomes (optimism); and recover from setbacks (resilience) (Luthans et al., 2007). As PsyCap is a state-like concept that is measurable and was empirically proven to influence work and organisational outcomes such as performance and employee well-being, Dollwet and Reichard (2014) state that it can be applied in a cross-cultural work setting. They describe the four PsyCap components in a cross-cultural context as follows (Dollwet \& Reichard, 2014; Reichard et al., 2014):

- Cross-cultural self-efficacy: People with high levels of crosscultural self-efficacy have a strong self-belief that they can communicate successfully with others from other cultural groups or in diverse settings. It also contributes to people's willingness to make the effort to understand others and to adapt to new environments (Earley \& Ang, 2003) and relates to various positive work outcomes.

- Cross-cultural hope: People with high cross-cultural hope have found ways about problems relating to crosscultural interactions and can stay focused on the setting and achieving of goals within cross-cultural environments (Reichard et al., 2014).

- Cross-cultural optimism: Cross-cultural interaction is often difficult, but people with high cross-cultural optimism remain positive and motivated during cross-cultural interaction and 'expect the best when interacting with people from different cultures' (Dollwet \& Reichard, 2014, p. 1672).

- Cross-cultural resilience: People with cross-cultural resilience are able to keep up their performance despite obstacles, such as language difficulties, cross-cultural conflict or other cross-cultural issues. Cross-cultural environments often bring uncertainty, and the challenges underlying interactions in cross-cultural work environments are often rooted in their novelty. Therefore, resilience is of great personal value in cross-cultural environments as it helps people to cope with uncertainty and adapt to novel situations (Reichard et al., 2014).

The four components of cross-cultural PsyCap interact to assist employees in successfully navigating through crosscultural interactions. The 'unique aspects of cross-cultural PsyCap lie in its four-factor structure emphasizing complementary psychological resources rooted in the theoretical foundations of positive PsyCap' (Dollwet \& Reichard, 2014, p. 169). Dollwet and Reichard's (2014) study found that there was a negative relationship between crosscultural PsyCap and ethnocentrism, while cross-cultural PsyCap had positive associations with cultural intelligence, adjustment and openness to experience.

\section{Psychological well-being (work engagement and burnout)}

Work engagement and burnout are indicators of psychological well-being (Schaufeli \& Bakker, 2004). Work engagement is defined as a 'positive, fulfilling, work-related state of mind' 
that is characterised by 'vigour, dedication and absorption' (Schaufeli, Salanova, González-Romá, \& Bakker, 2002, p. 74). While work engagement was originally characterised by these three components, later research indicated vigour and dedication as its core components (Schaufeli, 2014; Schaufeli \& Bakker, 2004; Taris, Ybema, \& Van Beek, 2017).

Vigour refers to the willingness to apply high levels of energy to one's work and to invest in one's work activities, and to persevere in challenging circumstances. Vigour refers to an employee's attitude (also known as trait engagement or the physical component of engagement) towards the work environment that includes colleagues, customers and the organisation (Schaufeli \& Bakker, 2003; Schaufeli, Martínez, Pinto, Salanova, \& Bakker, 2002). Dedication refers to the cognitive component or state engagement and is defined as the involvement of an employee in his or her work that creates significance, pride, inspiration and challenge (Schaufeli \& Bakker, 2003; Schaufeli et al., 2002b).

While Maslach, Jackson and Leiter (1996) initially regarded burnout as the antithesis of work engagement, Schaeufeli et al. (2002b) argued that the absence of burnout is not engagement. Maslach (1993) defines burnout as consisting of three components, namely, emotional exhaustion, cynicism and personal accomplishment. However, Schaufeli and Bakker (2004) regard emotional exhaustion and cynicism as the core components of burnout. Emotional exhaustion is defined as being physically and emotionally tired, and the overextension of one's emotional resources. In order to cope with the situation, employees start withdrawing from their work, leading to cynicism. Cynicism is defined as being indifferent and having a negative attitude towards others (Taris et al., 2017).

\section{The relationship between cross-cultural psychological capital and psychological well-being}

The positive outcomes of employees' ability to adjust to and operate effectively in cross-cultural work environments have been studied for some time. For example, a meta-analytical study by Bhaskar-Shrinivas, Harrison, Shaffer and Luk (2005) explained how cross-cultural adjustment had a positive effect on the performance and job satisfaction of expatriates. In a South African study, Serfontein (2014) found diversity problems to be positively related to symptoms of burnout, while those who experienced diversity problems also had lower levels of work engagement. The relationship between employees' ability to adjust to intercultural environments and their levels of work engagement was also explored by Selmer and Lauring (2015). In a study involving expatriates in Greater China, they found that work engagement had a stronger relationship with employees' ability to adjust to their jobs than with interaction adjustment or general adjustment. The results of a study including international students in Taiwan showed a significant relationship between cultural intelligence and psychological well-being (Yang \& Chang, 2017). Those with higher levels of cultural intelligence are able to use their cultural understanding of others to help them determine the most appropriate action to take in different cultural contexts. They also have a greater interest in adjusting themselves to different cultural environments.

Although several studies relating workplace PsyCap to different work outcomes are available, studies measuring cross-cultural PsyCap specifically are very limited. A study by Liu (2014) showed that cross-cultural PsyCap significantly predicted job performance, as well as psychological and socio-cultural adjustment, of Chinese expatriates, while Dollwet and Reichard's (2014) study indicated that employees with higher levels of cross-cultural PsyCap measured higher on sociocultural adjustment. With regard to workplace PsyCap, previous international and South African studies indicated PsyCap to be a significant predictor of psychological well-being. In a study with Chinese nurses, Wang, Lui, Zou, Hao and $\mathrm{Wu}$ (2017) found that PsyCap could be a positive resource to improve the work engagement of the nurses, especially with respect to hope and optimism. In an Italian study in the public sector, an intervention programme based on improving PsyCap found a positive relationship between PsyCap and work engagement (Costantini et al., 2017). In South African studies, Du Plessis (2014) found that PsyCap made the biggest unique contribution to work engagement, while Bekker (2016) found PsyCap to be a predictor of work engagement. Other studies indicate that PsyCap helps prevent burnout. In a South African study with mineworkers, Nel and Kotzé (2017) found that the mineworkers had low levels of burnout and high levels of PsyCap (including all four components), indicating that PsyCap is likely to improve the psychological well-being. Kotzé (2018a) measured the influence of job resources and PsyCap on both work engagement and burnout and found that satisfaction with job resources was negatively related to burnout and positively related to work engagement, and that PsyCap had a positive influence on satisfaction with job resources. Therefore, satisfaction with job resources mediated the influence of PsyCap on burnout and work engagement.

\section{Theoretical hypotheses}

In light of the previous research, it is proposed that employees who gain higher levels of cross-cultural PsyCap may be less prone to burnout and may have higher levels of work engagement. Figure 1 shows the conceptual model and hypotheses formulated.

Hypothesis 1: Cross-cultural PsyCap has a statistically significant positive influence on the vigour component of work engagement.

Hypothesis 2: Cross-cultural PsyCap has a statistically significant positive influence on the dedication component of work engagement.

Hypothesis 3: Cross-cultural PsyCap has a statistically significant negative influence on the cynicism component of burnout. 


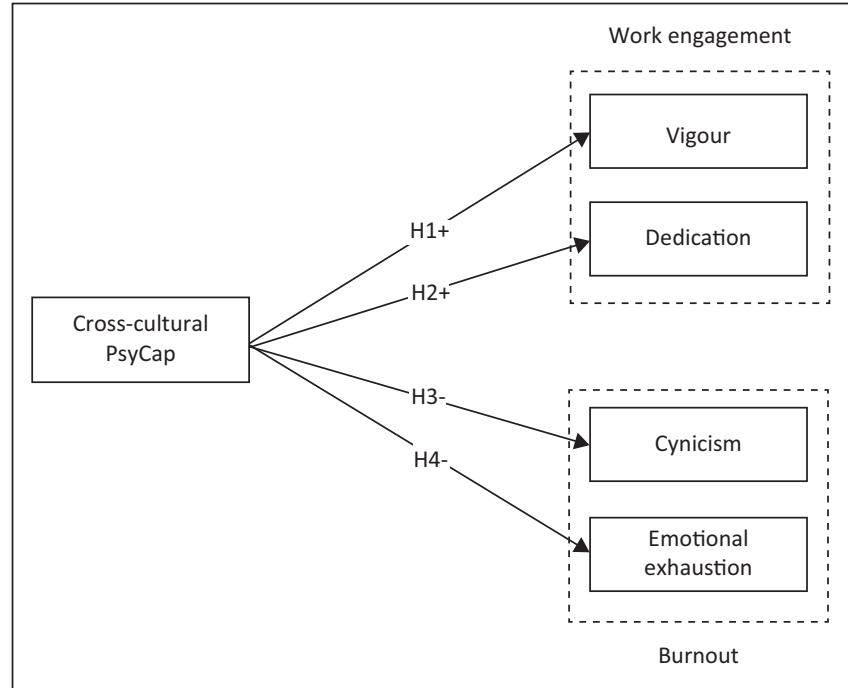

FIGURE 1: The conceptual model and hypotheses.

Hypothesis 4: Cross-cultural PsyCap has a statistically significant negative influence on the emotional exhaustion component of burnout.

\section{Research design Research approach}

A cross-sectional design with a survey data collection technique was applied in this study.

\section{Research method}

\section{Participants}

A total of 213 employees from different private and public organisations took part in the study. The mean age of the respondents was 36.35 years (median $[\mathrm{MD}]=36$; standard deviation $[\mathrm{SD}]=7.473)$. The majority were between 26 and 45 years of age (85.91\%). Furthermore, $55.87 \%(n=119)$ were men.

The following language groups were represented: indigenous African languages (approximately 67\%; $n=142$ ), Afrikaans (approximately 25\%; $n=53$ ) and English (approximately 8\%; $n=18)$. In terms of ethnicity, about $68 \%(n=145)$ indicated that they were blacks, $18 \%$ were whites $(n=39), 11 \%$ were mixed race $(n=23)$ and $3 \%$ were Asians $(n=6)$. Nearly $13 \%$ $(n=27)$ respondents had five or less years of work experience, $31 \%(n=66)$ had $6-10$ years of experience, $25 \%(n=54)$ had $11-15$ years of experience, while about $31 \%(n=66)$ had more than 16 years of experience.

\section{Measuring instruments}

Cross-cultural PsyCap: Dollwet and Reichard's (2014) crosscultural PsyCap questionnaire was used to measure crosscultural competence. These authors adapted the workplace PCQ-24 of Luthans et al. (2007) to the domain of crosscultural interactions (Reichard et al., 2014). It consists of 20 items that include cross-cultural self-efficacy ('I believe I can succeed at almost anything I set my mind to when working across cultures'), cross-cultural hope ('There are lots of ways around any problem that I face when interacting with individuals from different cultures'), cross-cultural optimism ('I am optimistic about my future cross-cultural interactions') and cross-cultural resilience ('Even when things are tough, I can interact quite well with people from different cultures') (Dollwet \& Reichard, 2014, p. 1689). Items were rated on a five-point Likert-type scale ranging from 1 (strongly disagree) to 5 (strongly agree). The overall cross-cultural Psycap questionnaire applied to the South African sample demonstrated strong reliability (pre-test $\alpha=0.95$, post-test $\alpha=0.92$, post-post-test $\alpha=0.93$ ), while confirmatory factor analysis (CFA) confirmed the higher-order factor construct proposed for cross-cultural PsyCap in both South African and US samples (Reichard et al., 2014).

Psychological well-being: Relevant items from Maslach Burnout Inventory-General Survey (MBI-GS) (Schutte, Toppinen, Kalimo \& Schaufeli, 2000) and the Utrecht Work Engagement Scale (UWES-9) (Schaufeli, Bakker, \& Salanova, 2006) were used to measure burnout and work engagement. Items were rated on a seven-point Likert scale, with options ranging from 'never true of me' to 'almost always true of me'. Burnout was measured by means of emotional exhaustion (Ex) (i.e. 'I feel used up at the end of the workday') and cynicism (Cy) (i.e. 'I have become less interested in my work since I started this job'). In South African studies, the Cronbach's alpha $\alpha$ coefficients of $0.86-0.88$ were estimated for emotional exhaustion and 0.74-0.80 for cynicism (Joubert \& Rothmann, 2007; Rothmann, 2008). A South African study by Rothmann and Joubert (2007) found the fit of the two-factor MBI model to be acceptable, with all the fit indices higher than 0.90 . Work engagement was measured by means of vigour (i.e. 'At my work, I feel strong and vigorous') and dedication (i.e. 'My job inspires me'). A cross-national study by Schaufeli et al. (2006) indicated Cronbach's $a$ values between 0.60 and 0.88 (median $=0.77$ ) for vigour and between 0.75 and 0.90 (median $=0.85$ ) for dedication. Rothmann and Joubert (2007) found the two-factor UWES model to be acceptable as the fit indices were all higher than 0.90 .

\section{Statistical analysis}

Partial least squares (PLS) and structural equations modelling (SEM) (SmartPLS version 3.2.8) were used to test the hypotheses (Hair, Ringle, \& Sarstedt, 2011). A two-step approach was followed (Hair, Hult, Ringle, \& Sarstedt, 2017). Firstly, the measurement model was assessed for internal consistency and construct validity. Considering that cross-cultural PsyCap is a reflective-reflective secondorder construct consisting of four underlying first-order reflective constructs, the first-order constructs and the four dependent variables were first assessed for internal consistency and construct validity. Then, the second-order construct was assessed for internal consistency and validity. The assessment of internal consistency entailed calculating the composite reliability $(\mathrm{CR})$ value for each construct. The 
CR value should be 0.7 or higher. To assess convergent validity, the outer loadings must be 0.7 or higher and statistically significant, and the average variance extracted (AVE) for each construct must be 0.5 or higher. To assess discriminant validity, the heterotrait-monotrait (HTMT) ratio of correlations was used (Henseler, Ringle, \& Sarstedt, 2015). Based on the HTMT ratio of correlations, the ratio between a pair of constructs must not exceed 0.85 for evidence of discriminant validity.

Secondly, the structural model was assessed. As in the case of PLS-SEM, $p$-values were calculated by using bias-corrected bootstrapping (5000 subsamples).

\section{Results}

\section{Measurement model results}

Two steps were followed in assessing the measurement model. Firstly, the original measurement model as in the questionnaires was assessed for internal consistency and

TABLE 1: Results of the original measurement model assessment (all first-order constructs).

\begin{tabular}{|c|c|c|c|c|c|c|}
\hline \multicolumn{2}{|c|}{ Constructs } & Items & $\begin{array}{l}\text { Outer } \\
\text { loadings }\end{array}$ & $\begin{array}{c}p \\
\text { (two-tailed) }\end{array}$ & CR & AVE \\
\hline \multirow{3}{*}{\multicolumn{2}{|c|}{ Vigour }} & VIG1 & 0.816 & 0.000 & 0.842 & 0.641 \\
\hline & & VIG2 & 0.863 & 0.000 & & \\
\hline & & VIG3 & 0.715 & 0.000 & & \\
\hline \multirow{3}{*}{\multicolumn{2}{|c|}{ Dedication }} & DED1 & 0.920 & 0.000 & 0.934 & 0.826 \\
\hline & & DED2 & 0.946 & 0.000 & & \\
\hline & & DED3 & 0.858 & 0.000 & & \\
\hline \multirow{4}{*}{\multicolumn{2}{|c|}{ Cynicism }} & CYN1 & 0.830 & 0.000 & 0.907 & 0.708 \\
\hline & & CYN2 & 0.865 & 0.000 & & \\
\hline & & CYN3 & 0.879 & 0.000 & & \\
\hline & & CYN4 & 0.790 & 0.000 & & \\
\hline \multirow{5}{*}{\multicolumn{2}{|c|}{ Emotional exhaustion }} & EE1 & 0.881 & 0.000 & 0.911 & 0.673 \\
\hline & & EE2 & 0.801 & 0.000 & & \\
\hline & & EE3 & 0.788 & 0.000 & & \\
\hline & & EE4 & 0.770 & 0.000 & & \\
\hline & & EE5 & 0.856 & 0.000 & & \\
\hline \multirow{20}{*}{$\begin{array}{l}\text { Cross- } \\
\text { cultural } \\
\text { PsyCap }\end{array}$} & \multirow[t]{9}{*}{ Self-efficacy } & CEFF1 & 0.790 & 0.000 & 0.924 & 0.577 \\
\hline & & CEFF2 & 0.759 & 0.000 & & \\
\hline & & CEFF3 & 0.755 & 0.000 & & \\
\hline & & CEFF4 & 0.696 & 0.000 & & \\
\hline & & CEFF5 & 0.826 & 0.000 & & \\
\hline & & CEFF6 & 0.799 & 0.000 & & \\
\hline & & CEFF7 & 0.807 & 0.000 & & \\
\hline & & CEFF8 & 0.656 & 0.000 & & \\
\hline & & CEFF9 & 0.731 & 0.000 & & \\
\hline & \multirow[t]{4}{*}{ Hope } & $\mathrm{CH} 1$ & 0.799 & 0.000 & 0.862 & 0.611 \\
\hline & & $\mathrm{CH} 2$ & 0.811 & 0.000 & & \\
\hline & & $\mathrm{CH} 3$ & 0.819 & 0.000 & & \\
\hline & & $\mathrm{CH} 4$ & 0.691 & 0.000 & & \\
\hline & \multirow[t]{4}{*}{ Optimism } & COPT1 & 0.720 & 0.000 & 0.869 & 0.624 \\
\hline & & COPT2 & 0.766 & 0.000 & & \\
\hline & & СОРТ3 & 0.840 & 0.000 & & \\
\hline & & COPT4 & 0.828 & 0.000 & & \\
\hline & \multirow[t]{3}{*}{ Resilience } & CRES1 & 0.914 & 0.000 & 0.923 & 0.800 \\
\hline & & CRES2 & 0.929 & 0.000 & & \\
\hline & & CRES3 & 0.837 & 0.000 & & \\
\hline
\end{tabular}

CYN, Cynicism; DED, dedication; EE, emotional exhaustion; $\mathrm{CH}$, cross-cultural hope; COPT, cross-cultural optimism; CRES, cross-cultural resilience; CEFF, cross-cultural self-efficacy; VIG, vigour; CR, composite reliability; AVE, average variance extracted. construct validity. Based on the results of the assessment, modifications were made to the measurement model in order to address problematic discriminant validity issues.

In the assessment of the original measurement model (see Table 1), adequate internal consistency and convergent validity were confirmed for all first-order constructs. However, as seen in Table 2, discriminant validity based on the HTMT ratio of correlations could not be confirmed between dedication and vigour, or between cross-cultural resilience and cross-cultural self-efficacy (two first-order constructs of cross-cultural PsyCap). Taking into account that the HTMT ratio is based on correlations, an inspection of the correlations between the items measuring dedication and vigour and the items measuring cross-cultural resilience and cross-cultural self-efficacy was conducted. High correlations between the items measuring each pair of constructs were identified and items forming part of these correlations were systematically removed from the measurement model up to the point that an acceptable HTMT ratio $(<0.85)$ was reached. This was achieved by removing VIG3, CEFF5 and CEFF7.

The results of the modified measurement model are presented in Table 1, while Table 3 presents the results of the HTMT ratio between the first-order constructs. All ratios are below the threshold of 0.85 (Table 3).

Table 4 provides the descriptive information of the constructs.

The results for the second-order construct cross-cultural PsyCap is presented in Table 5. The second-order construct exhibited adequate internal consistency and convergent validity to continue with the hypotheses testing.

TABLE 2: Heterotrait-monotrait ratio of correlations (first-order constructs).

\begin{tabular}{lccccccc}
\hline Construct & CYN & DED & EE & CH & COPT & CRES & CEFF \\
\hline DED & 0.649 & - & - & - & - & - & - \\
EE & 0.715 & 0.448 & - & - & - & - & - \\
CH & 0.230 & 0.210 & 0.211 & - & - & - & - \\
COPT & 0.088 & 0.124 & 0.192 & 0.704 & - & - & - \\
CRES & 0.272 & 0.192 & 0.317 & 0.629 & 0.736 & - & - \\
CEFF & 0.223 & 0.263 & 0.243 & 0.764 & 0.784 & $\mathbf{0 . 8 5 4}$ & - \\
VIG & 0.575 & $\mathbf{0 . 9 0 4}$ & 0.526 & 0.363 & 0.201 & 0.265 & 0.354 \\
\hline
\end{tabular}

DED, Dedication; EE, emotional exhaustion; CYN, cynicism; $\mathrm{CH}$, cross-cultural hope; COPT, cross-cultural optimism; CRES, cross-cultural resilience; CEFF, cross-cultural self-efficacy; VIG, vigour.

Bold significance.

TABLE 3: Heterotrait-monotrait ratio of correlations (all first-order constructs).

\begin{tabular}{lccccccc}
\hline Construct & CYN & DED & EE & CH & COPT & CRES & CEFF \\
\hline DED & 0.649 & - & - & - & - & - & - \\
EE & 0.715 & 0.448 & - & - & - & - & - \\
CH & 0.230 & 0.210 & 0.211 & - & - & - & - \\
COPT & 0.088 & 0.124 & 0.192 & 0.704 & - & - & - \\
CRES & 0.272 & 0.192 & 0.317 & 0.629 & 0.736 & - & - \\
CEFF & 0.202 & 0.253 & 0.228 & 0.778 & 0.788 & 0.836 & - \\
VIG & 0.440 & 0.703 & 0.366 & 0.335 & 0.211 & 0.279 & 0.325 \\
\hline
\end{tabular}

CYN, Cynicism; DED, dedication; EE, emotional exhaustion; $\mathrm{CH}$, cross-cultural hope; COPT, cross-cultural optimism; CRES, cross-cultural resilience; CEFF, cross-cultural self-efficacy; VIG, vigour. 
TABLE 4: Descriptive information of constructs.

\begin{tabular}{lcccccccccc}
\hline Construct & M & SD & CYN & DED & EE & CH & COPT & CRES & CEFF & VIG \\
\hline CYN & 1.984 & 1.293 & 1.000 & - & - & - & - & - & - & - \\
DED & 6.091 & 1.134 & -0.558 & 1.000 & - & - & - & - & - & - \\
EE & 2.714 & 1.400 & 0.618 & -0.404 & 1.000 & - & - & - & - & - \\
CH & 5.140 & 0.937 & -0.194 & 0.186 & -0.170 & 1.000 & - & - & - & - \\
COPT & 5.053 & 0.929 & -0.069 & 0.112 & -0.167 & 0.560 & 1.000 & - & - & - \\
CRES & 5.203 & 0.787 & -0.239 & 0.169 & -0.282 & 0.528 & 0.615 & 1.000 & - & - \\
CEFF & 5.238 & 0.805 & -0.178 & 0.229 & -0.209 & 0.651 & 0.659 & 0.733 & 1.000 & - \\
VIG & 5.505 & 1.364 & -0.324 & 0.554 & -0.277 & 0.246 & 0.160 & 0.224 & 0.261 & 1.000 \\
\hline
\end{tabular}

Note: Correlations below the diagonal.

$M$, Mean; SD, standard deviation; CYN, cynicism; DED, dedication; EE, emotional exhaustion $\mathrm{CH}$, cross-cultural hope; COPT, cross-cultural optimism; CRES, cross-cultural resilience; CEFF, cross-cultural self-efficacy; VIG, vigour.

TABLE 5: Measurement model results of the second-order construct.

\begin{tabular}{llcccc}
\hline $\begin{array}{l}\text { Second-order } \\
\text { construct }\end{array}$ & $\begin{array}{l}\text { First-order } \\
\text { constructs }\end{array}$ & $\begin{array}{c}\text { Path } \\
\text { coefficients }\end{array}$ & $\begin{array}{c}p \\
\text { (two-tailed) }\end{array}$ & CR & AVE \\
\hline Cross-cultural & Self-efficacy & 0.932 & 0.000 & & \\
PsyCap & Hope & 0.787 & 0.000 & 0.910 & 0.716 \\
& Optimism & 0.816 & 0.000 & & \\
& Resilience & 0.843 & 0.000 & & \\
\hline
\end{tabular}

$\mathrm{CR}$, composite reliability; AVE, average variance extracted.

TABLE 6: Heterotrait-monotrait ratio of correlations (second-order construct and the dependent variables).

\begin{tabular}{lcccc}
\hline Construct & CSKILLS & CYN & DED & EE \\
\hline CYN & 0.218 & - & - & - \\
DED & 0.226 & 0.649 & - & - \\
EE & 0.259 & 0.715 & 0.448 & - \\
VIG & 0.325 & 0.44 & 0.703 & 0.366 \\
\hline
\end{tabular}

CSKILLS, Cross-cultural PsyCap; CYN, cynicism; DED, dedication; EE, emotional exhaustion; VIG, vigour.

Table 5 shows the HTMT ratio of correlations between the second-order construct and the four dependent variables. All HTMT ratios of correlations in Table 6 are below 0.85. Further evidence of discriminant validity in the measurement model is provided by these results.

\section{Testing of hypotheses}

Figure 2 shows the results of the testing of the hypotheses. All four hypotheses were accepted. The positive influence of cross-cultural PsyCap was stronger on vigour than on dedication, and the negative influence of cross-cultural PsyCap was stronger on emotional exhaustion than on cynicism. Confidence interval results are provided in Table 7.

\section{Ethical considerations}

All the respondents participated in the study voluntarily. They were asked to sign a consent form that guaranteed anonymity, confidentiality and publication of only aggregate data.

\section{Discussion}

\section{Outline of results}

The purpose of the study was to investigate the influence of employees' cross-cultural PsyCap on their psychological well-being (i.e. burnout and work engagement). Based on the findings of previous research on PsyCap, it was hypothesised

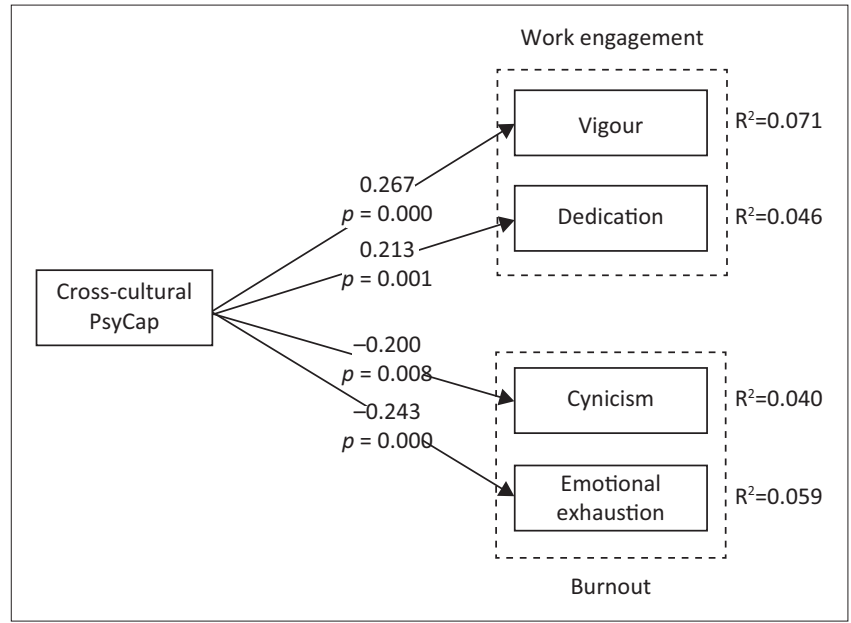

FIGURE 2: Relationships between cross-cultural PsyCap and psychological wellbeing (work engagement and burnout).

TABLE 7: Confidence interval results of the structural model.

\begin{tabular}{lccc}
\hline Relationship & $\begin{array}{c}\text { Standardised } \\
\text { coefficient }\end{array}$ & $\begin{array}{c}\text { 95\% BCCl lower } \\
\text { limit (2.5\%) }\end{array}$ & $\begin{array}{c}\text { 95\% BCCl upper } \\
\text { limit (97.5\%) }\end{array}$ \\
\hline Cross-cultural PsyCap -> Vigour & 0.267 & 0.143 & 0.377 \\
Cross-cultural PsyCap -> Dedication & 0.213 & 0.101 & 0.334 \\
Cross-cultural PsyCap -> Cynicism & -0.200 & -0.338 & -0.067 \\
$\begin{array}{l}\text { Cross-cultural PsyCap -> Emotional } \\
\text { exhaustion }\end{array}$ & -0.243 & -0.355 & -0.144 \\
\hline
\end{tabular}

$\mathrm{BCCl}$, Bias-corrected confidence interval.

that cross-cultural PsyCap will have a significant positive influence on vigour (H1) and dedication (H2) and a significant negative influence on cynicism (H3) and emotional exhaustion (H4). All these hypotheses were accepted. However, the positive influence of cross-cultural PsyCap was stronger on vigour than on dedication, and the negative influence of cross-cultural PsyCap was stronger on emotional exhaustion than on cynicism.

The findings support various previous studies and the JD-R model relating to workplace PsyCap that indicated that PsyCap had a positive influence on work engagement and a negative influence on burnout (Bekker, 2016; Du Plessis, 2014; Kotzé, 2018a, 2018b; Wang et al., 2017) and support the hypothesis that cross-cultural PsyCap will yield the same result as PsyCap. Also, in line with previous research on PsyCap, cross-cultural PsyCap had a stronger influence on both vigour (a component of engagement) and emotional exhaustion (a component of burnout). It is interesting to note that, according to Taris et al. (2017), both these components relate to the energetic component of psychological wellbeing. They state that vigour and emotional exhaustion focus on the energetic component of psychological wellbeing, while cynicism and dedication refer to employees' commitment. Therefore, it can be deduced that cross-cultural PsyCap has a stronger influence on the energetic components of psychological well-being than on the commitment components thereof. Avey, Luthans, Smith, and Palmer (2010) indicated that the acquiring and maintaining of personal resources, such as cross-cultural PsyCap, function both as a means and an end. In this instance, as a means it assists in 
achieving success in cross-cultural situations. For example, high levels of ethnocentrism hinder the success of individuals working across cultures. Cross-cultural PsyCap has a negative relationship with ethnocentrism and therefore increases employees' chances of being successful in such environments (Dollwet \& Reichard, 2014). As an end, it results in better psychological well-being. According to Hobfoll's (2011) COR theory, employees seek to gain resources so that their resource gain can lead to the creation or accumulation of other resources that can enhance their psychological well-being.

\section{Practical implications}

Cross-cultural interactions are often emotionally charged and may lead to negative emotions and negative psychological well-being that can deplete personal resources. Cross-cultural PsyCap focuses on positive emotions and can provide a defence against these negative emotions. It can also assist in broadening resources that can lead to a more open view when it comes to other cultures (Reichard et al., 2014). Crosscultural PsyCap should be considered as part of the personal resources that are identified in the JD-R model and COR theory. However, the development of cross-cultural competence demands more than a once-off intervention where knowledge and skills related to other cultures are provided. It requires the introduction and building of crosscultural PsyCap, continuous learning and reinforcement, as well as organisational support. It is therefore an ongoing process (Du Plessis, 2014; Kealy \& Protheroe, 1996; Reichard et al., 2014).

\section{Limitations and recommendations}

The study was limited to a relatively small convenience sample. The implication thereof was that it was too small to conduct a multi-group analysis (distinguishing between employees from private and public sector organisations). In the future, the two groups can be tested separately when larger numbers of participants are available. Also, the sample size allowed theory building by using SmartPLS. However, a larger sample would have allowed the use of covariancebased structural equation modelling for more rigorous testing of the theory. Future research can replicate the model on larger, purposefully selected samples. Because research on the influence of cross-cultural PsyCap is very limited, the influence thereof on other work outcomes, such as organisational commitment and performance, can also be explored.

\section{Conclusion}

South Africa is known for its diversity and this is reflected in the workplace. However, most South African research relating to the influence of personal resources on employee well-being focuses on the role of psychological resources, such as PsyCap. Very little research is available on the effect of cross-cultural PsyCap on psychological well-being. This research contributes to filling the gap in the literature regarding the role of cross-cultural psychological resources in the psychological well-being of employees working in cross-cultural environments. Increasing employees' cross-cultural PsyCap by means of programmes and continuous learning and reinforcement may prevent burnout and keep them more engaged in their work. Cross-cultural training assists with better cultural adjustment of employees because of more effective crosscultural interactions. These interventions usually include the sharing of information about the relevant cultures and the development of intercultural skills, such as crosscultural communication (Reichard et al., 2014). The focus of cross-cultural PsyCap on developing personal resources is an important factor that organisations must harness, as it provides a preventative perspective that can enhance employee well-being.

\section{Acknowledgements Competing interests}

The authors declare that they have no financial or personal relationship(s) which may have inappropriately influenced them in writing this article.

\section{Authors' contributions}

M.K. was responsible for conceptualisation, literature review, data gathering, discussion of results, practical implications, limitations and conclusion of the article. L.M. was responsible for literature review, discussion of results, practical implications, limitations and conclusion of the article.

\section{Funding information}

This research received no specific grant from any funding agency in the public, commercial, or not-for-profit sectors.

\section{Data availability statement}

Data sharing is not applicable to this article as no new data were created or analysed in this study.

\section{Disclaimer}

The views and opinions expressed in this article are those of the authors and do not necessarily reflect the official policy or position of any affiliated agency of the authors.

\section{References}

Ang, S., \& Inkpen, A. C. (2008). Cultural intelligence and offshore outsourcing success: A framework of firm-level intercultural capability. Decision Sciences, 39, 337-358. https://doi.org/10.1111/j.1540-5915.2008.00195.x

Avey, J. B., Luthans, F., Smith, R. M., \& Palmer, N. F. (2010). Impact of positive psychological capital on employee well-being over time. Journal of Occupational Health Psychology, 15, 17-28. https://doi.org/10.1037/a0016998

Bakker, A. B., \& Demerouti, E. (2008). Towards a model of work engagement. Career Development International, 13, 209-223. https://doi.org/10.1108/ 13620430810870476

Bekker, S. (2016). Exploring the relationship between psychological capital and work engagement. Master's mini-dissertation. Potchefstroom, South Africa: NorthWest University. 
Bhaskar-Shrinivas, P., Harrison, D. A., Shaffer, M. A., \& Luk, D. M. (2005). Input-based and time-based models of international adjustment: Meta-analytic evidence and theoretical extensions. Academy of Management Journal, 48, 257-281. https:// doi.org/10.5465/AMJ.2005.16928400

Chatman, J. A., \& Flynn, F. J. (2001). The influence of demographic heterogeneity on the emergence and consequences of cooperative norms in work teams. Academy of Management Journal, 44, 956-974. https://doi.org/10.5465/3069440

Costantini, A., De Paola, F., Ceschi, A., Sartori, R., Meneghini, A. M., \& Di Fabio A. (2017). Work engagement and psychological capital in the Italian public administration: A new resource-based intervention programme. SA Journal of Industrial Psychology, 43(0), a1413. https://doi.org/10.4102/sajip.v43i0.1413

De Dreu, C. K. W., \& West, M. A. (2001). Minority dissent and team innovation: The Co participation in decision making. Journal of $A$ ppl

1191-1201. https://doi.org/10.1037/0021-9010.86.6.1191

Deloitte. (2018). Human capital trends report for South Africa: The rise of the socia enterprise. Retrieved from http://www.talenttalks.net/2018-deloitte-humancapital-trends-report-south-africa.

Dollwet, M., \& Reichard, R. (2014). Assessing cross-cultural skills: Validation of a new measure of cross-cultural psychological capital. The International Journal of Human Resource Management, 25, 1669-1696. https://doi.org/10.1080/095851 92.2013.845239

Du Plessis, M. (2014). The relationship between authentic leadership, psychological capital, followership and work engagement. Doctoral dissertation. Bellville, South Africa: University of the Western Cape.

Earley, P. C., \& Ang, S. (2003). Cultural intelligence: Individual interactions across cultures. Stanford, CA: Stanford University Press.

Hair, J. F. Jr., Hult, G. T. M., Ringle, C. M., \& Sarstedt, M. (2017). A primer on partial least squares structural equation modeling (PLS-SEM) (2nd edn.). Thousand Oaks, CA: Sage.

Hair, J. F., Ringle, C. M., \& Sarstedt, M. (2011). PLS-SEM: Indeed a silver bullet. Journal of Marketing Theory and Practice, 19, 139-152. https://doi.org/10.2753/ MTP1069-6679190202

Henseler, J., Ringle, C. M., \& Sarstedt, M. (2015). A new criterion for assessing discriminant validity in variance-based structural equation modeling. Journal of the Academy of Marketing Science, 43, 115-135. https://doi.org/10.1007/ s11747-014-0403-8

Hobfoll, S. E. (2002). Social and psychological resources and adaptation. Review of General Psychology, 6, 307-324. https://doi.org/10.1037/1089-2680.6.4.307

Hobfoll, S. E. (2011). Conservation of resource caravans and engaged settings. Journal of Occupational and Organizational Psychology, 84, 116-122. https://doi org/10.1111/j.2044-8325.2010.02016.x

Javidan, M., \& Teagarden, M. B. (2011). Conceptualizing and measuring global mindset. In W. H. Mobley, M. Li, \& Y. Wang (Eds.), Advances in Global Leadership (Vol. 6, pp. 13-39). Bingley, UK: Emerald.

Johnson, J. P., Lenartowicz, T., \& Apud, S. (2006). Cross-cultural competence in international business: Toward a definition and a model. Journal of International Business Studies, 37, 525-543. https://doi.org/10.1057/palgrave.jibs.8400205

Joubert, J. H. M., \& Rothmann, S. (2007). Job demands, job resources, burnout and work engagement of managers at a platinum mine in the North West Province. South African Journal of Business Management, 38(3), 49-61.

Kealy, D. J., \& Protheroe, D. R. (1996). The effectiveness of cross-cultural training for expatriates: An assessment of the literature on the issue. International Journal of Intercultural Relations, 20, 141-165. https://doi.org/10.1016/0147-1767(96)00001-6

Kotzé, M. (2018a). How job resources and personal resources influence work engagement and burnout. African Journal of Economic and Management Studies, 9, 148-164. https://doi.org/10.1108/AJEMS-05-2017-0096

Kotzé, M. (2018b). The influence of psychological capital, self-leadership, and mindfulness on work engagement. South African Journal of Psychology, 48, 279-292. https://doi.org/10.1177/0081246317705812

Liu, G. (2014). The impact of cross-cultural psychological capital and social support on expatriate effectiveness: A study of Chinese expatriates. Doctoral dissertation. Auckland, New Zealand: The University of Auckland.

Luthans, F., Youssef, C. M., \& Avolio, B. J. (2007). Psychological capital: Developing the human competitive edge. New York, NY: Oxford University Press.

Luthans, F., \& Youssef-Morgan, C. M. (2017). Psychological capital: An evidence-based positive approach. Annual Review of Organizational Psychology and Organizationa Behavior, 4, 339-366. https://doi.org/10.1146/annurev-orgpsych-032516-113324
Maslach, C. (1993). Burnout: A multidimensional perspective. In W. B. Schaufeli, C. Maslach, \& T. Marek (Eds.), Professional burnout: Recent developments in theory and research (pp. 19-32). Washington, DC: Taylor \& Francis.

Maslach, C. Jackson, S. E., \& Leiter, M. P. (1996). Maslach burnout inventory: Test manual. Palo Alto, CA: Consulting Psychologists Press.

Nel, P., \& Kotzé, M. (2017). The influence of psychological resources on mineworkers' levels of burnout in a remote and isolated mining town in South Africa. The Extractive Industries and Society, 4, 885-892. https://doi.org/10.1016/j.exis.2017.10.002

Ng, K.-Y., \& Earley, P. C. (2006). Culture + intelligence: Old constructs, new frontiers. Group \& Organization Management, 31, 4-19. https://doi.org/10.1177/1059601105275251

Potgieter, E. (2017). SA reconciliation barometer survey: 2017 report. Institute for Justice and Reconciliation. Retrieved from http://www.ijr.org.za/home/wpcontent/uploads/2018/03/IJR-Barometer-Report-2017-WEB-final.pdf

Reichard, R. J., Dollwet, M., \& Louw-Potgieter, J. (2014). Development of crosscultural psychological capital and its relationship with cultural intelligence and ethnocentrism. Journal of Leadership \& Organizational Studies, 21, 150-164. https://doi.org/10.1177/1548051813515517

Rothmann, S. (2008). Job satisfaction, occupational stress, burnout and work engagement as components of work-related wellbeing. SA Journal of Industria Psychology, 34(3), 11-16. https://doi.org/10.4102/sajip.v34i3.424

Rothmann, S., \& Joubert, J. H. M. (2007). Job demands, job resources, burnout and work engagement of manager at a platinum mine in the North West Province. South African Journal of Business Management, 38(3), 49-61.

Schaufeli, W., \& Bakker, A. (2003). UWES Utrecht Work Engagement Scale: Preliminary manual (Version 1). Retrieved from https://www.academia.edu/31439118/ UWES_UTRECHT_WORK_ENGAGEMENT_SCALE_Preliminary_Manual.

Schaufeli, W. B. (2014). What is engagement? In C. Truss, R. Delbridge, R. Alfes, A. Shantz, \& E. Soane (Eds.), Employee engagement in theory and practice (pp. 15-35). London, UK: Routledge.

Schaufeli, W. B., \& Bakker, A. B. (2004). Job demands, job resources and their relationship with burnout and engagement: A multi-sample study. Journal of Organizational Behavior, 25, 293-315. https://doi.org/10.1002/job.248

Schaufeli, W. B., Bakker, A. B., \& Salanova, M. (2006). The measurement of workengagement with a short questionnaire: A cross-national study. Educational and Psychological Measurement, 66, 701-716. https://doi.org/10.1177/0013164405282471

Schaufeli, W. B., Martínez, I. M., Pinto, A. M., Salanova, M., \& Bakker, A. B. (2002a). Burnout and engagement in university students: A cross-national study. Journal of Cross-cultural Psychology, 33, 464-481. https://doi.org/10.1177/ 0022022102033005003

Schaufeli, W. B., Salanova, M., González-Romá, V., \& Bakker, A. B. (2002b). The measurement of engagement and burnout: A two sample confirmatory factor analytic approach. Journal of Happiness Studies, 3, 71-92. https://doi. org/10.1023/A:1015630930326

Schutte, N., Toppinen, S., Kalimo, R. \& Schaufeli, W. (2000). The factorial validity of the Maslach Burnout Inventory-General Survey (MBI-GS) across occupational groups and nations. Journal of Occupational and Organizational Psychology, 73, 53-66

Selmer, J., \& Lauring, J. (2015). Work engagement and intercultural adjustment. International Journal of Cross Cultural Management, 16, 33-51. https://doi. org/10.1177/1470595815622491

Serfontein, T. (2014). The role of perceived organisational support, diversity, engagement and burnout in the retention of employees. Master's thesis. Potchefstroom, South Africa: North-West University.

Taris, T. W., Ybema, J. F., \& Van Beek, I. (2017). Burnout and engagement: Identical twins or just close relatives? Burnout Research, 5, 3-11. https://doi.org/10.1016/j. burn.2017.05.002

Urciuoli, B. (2010). Entextualizing diversity: Semiotic incoherence in institutional discourse. Language \& Communication, 30, 48-57. https://doi.org/10.1016/j. langcom.2009.10.005

Wang, X., Liu, L., Zou, F., Hao, J., \& Wu, H. (2017). Associations of occupational stressors, perceived organizational support, and psychological capital with work engagement among Chinese female nurses. BioMed Research International, 2017, 11. https://doi.org/10/1155/2017/5284628.

Yang, T.-P., \& Chang, W.-W. (2017). The relationship between cultural intelligence and psychological well-being with the moderating effects of mindfulness: A study of international students in Taiwan. European Journal of Multidisciplinary Studies, 2 384-391. https://doi.org/10.26417/ejms.v5i1.p384-391 